\title{
An Empirical Study of Readers' Associations with Multilingual Advertising: The Case of French, German and Spanish in Dutch Advertising
}

\author{
Jos Hornikx, Frank van Meurs and Marianne Starren \\ Business Communication Studies, Centre for Language Studies, \\ Radboud University Nijmegen, The Netherlands
}

\begin{abstract}
In multilingual advertising, a foreign language is often used for symbolic purposes. In non-French-speaking countries, for instance, French is said to be associated with charm and style. The assumption is that the associations carried by the foreign language are transferred to the product that is advertised. A product advertised using French would thus also be seen as charming and stylish. Although a number of suggestions have been made as to the associations evoked by particular foreign languages, it has never been tested what associations are actually evoked in the minds of consumers. In an experimental study, 78 Dutch respondents were asked to write down their associations with two advertisements for one product that were identical except for the foreign language in which they were written (French, German or Spanish). We investigated the kinds of associations evoked, the number of associations, their valence (positive, negative, neutral) and participants' appreciation of the foreign language advertisement. Results showed that the different languages evoked partly different associations, and that the valence of the associations, and not their number, affected participants' preference for the advertisement. Participants preferred the ad with the highest number of positive associations and the lowest number of negative associations.
\end{abstract}

\section{doi: $10.2167 / j m m d 482.0$}

Keywords: country-of-origin effect, culture, foreign languages, multilingualism, symbolic meaning

The use of foreign languages in advertising is common practice. No special effort is required to find examples such as French slogans in Dutch television commercials, English banners on Hungarian web pages and Italians words in English print advertisements. This kind of advertising is called multilingual advertising, which has been defined as 'the appearance of a number of different languages or voices in a market-discourse situation' (Kelly-Holmes, 2005: 25). Multilingual advertising is not only found in Europe, but also in other parts of the world, such as the USA (Petrof, 1990), South America (Alm, 2003) and Asia (Haarmann, 1989). The most frequently used foreign language in advertising across the world is English (Bhatia, 1992; Piller, 2003). Gerritsen (1996), for instance, analysed the frequency with which English was used in Dutch print advertisements. Of the 648 ads in her corpus, 137 were partly in 
English and 25 were even fully in English. However, languages other than English are also used in Dutch advertising, albeit to a lesser extent (Hornikx et al., 2004). One factor that may be conducive to the occurrence of multilingual advertising in a country such as the Netherlands may be this country's physical closeness to English-, French- and German-speaking countries. Moreover, the Dutch are said to have relatively high foreign language skills. In the 2006 Eurobarometer survey, citizens of European Union countries were asked, amongst other things, whether or not they thought they were able to hold a conversation in languages excluding their mother tongue. Of the Dutch respondents, 87\% claim they can hold a conversation in English, 70\% in German and 29\% in French, and 5\% in Spanish (European Commission, 2006: 152). Furthermore, Dutch respondents have a positive attitude towards foreign languages. They, for instance, prefer watching foreign films and TV programmes with subtitles rather than dubbed (European Commission, 2006: 136).

So far two factors have been mentioned that may contribute to the use of foreign languages in advertising in the Netherlands: the country's short distance from countries with other languages, and the language skills and attitudes of the Dutch. Although these factors may be relevant, we believe that it is possible to give a more fundamental explanation for the use of foreign languages in advertising. Kelly-Holmes (2005) distinguishes between a referential and a symbolic function of language usage in multilingual advertising. Advertising discourse may use foreign languages as a means of communication with speakers of a minority language in a country (e.g. Spanish in the USA), or as a linguistic symbol that creates positive associations in the minds of the receivers of the advertisement, respectively. Both forms of language use are endpoints on a continuum, which means that advertisements have both a communicative and a symbolic function. KellyHolmes argues that, most frequently, the use of foreign languages in advertising has primarily a symbolic function. Such language use can be characterised as linguistic fetish, which means that the symbolic associations with a language utterance are more important than what the utterance literally refers to. Thus, linguistic fetish relies on associations evoked in receivers of multilingual advertisements. As far as we know, there has been very little empirical research into what kinds of associations foreign languages in advertising actually evoke. In this paper, therefore, we will report on an experiment that was conducted to investigate what kind of associations are evoked by foreign language use, what their valence is (positive, negative or neutral), and how these associations relate to people's appreciation of an advertisement. Below, we will first discuss how foreign language use is said to make advertisements more effective.

\section{Linguistic Fetish in Multilingual Advertising}

The two main reasons for the use of foreign languages in advertising are attracting attention (Petrof, 1990; Sella, 1993), and - especially - creating a favourable image of the brand and the product (e.g. Gerritsen et al ., 2000; Piller, 2003). Drawing attention by using Italian or French in advertising in the Netherlands would for instance appear to be a potentially effective strategy, as 
these languages are relatively infrequent in Dutch advertising, and may, therefore, be all the more striking. As for the image that is created by the use of a foreign language, this image benefits from the associations that the language evokes. On this point, there appears to be a difference between English and other foreign languages (Hornikx et al., 2004; Kelly-Holmes, 2005; Piller, 2003). The use of English in advertising is usually not associated with a particular country (e.g. UK), but rather with the status of English as a world language, whereas other foreign languages are used because of their associations with the countries where they are spoken.

One of the first scholars to deal with the symbolic meaning of foreign words in advertising was Haarmann (1989), who investigated the use of European languages in advertising in Japan. Haarmann found that languages such as English, French, German and Spanish occurred frequently in Japanese advertising. Moreover, it appeared that these languages were not used randomly, but that their use depended on the type of product that was advertised. French, for instance, was frequently used in advertising for products such as watches, cars, bags and perfume. As most Japanese cannot read or understand European languages, Haarmann argues that these languages must have a symbolic meaning. For instance, French seems to be associated with elegance, taste and attractiveness (Haarmann, 1989: 11). KellyHolmes (2005) explains how linguistic fetish is accomplished. Foreign languages are not used arbitrarily in advertising. Generally, they are used when the specific language fits with the product, and with a relevant quality of the country where this language is spoken. This fit is related to the countryof-origin effect, which holds that it is more effective to relate a product to a country that consumers associate with this product than to another country. Examples of countries of origin and the products associated with them are France and wine, Germany and beer, and the Netherlands and cheese.

The country-of-origin effect can be maximised by using the language of the country of origin, such as French ('vin'), German ('Bier') and Dutch ('kaas'), respectively (Kelly-Holmes, 2000). Thus, whether a company decides to use a foreign language, and whether such a decision is wise, depends on what KellyHolmes (2000: 71) calls a 'cultural competence hierarchy', which 'preordains those products particular countries are "permitted" to produce'. A car is an example of the kind of product that, in the eyes of most Europeans, Germany can 'legitimately' manufacture. The German carmaker Audi, for instance, uses its original German slogan 'Vorsprung durch Technik' in non-German-speaking countries (Kelly-Holmes, 2005). In this example, the relationships between the country (Germany), the language (German), the product (car) and the competence (technical quality) are relatively straightforward. The cultural competence hierarchy also explains why German brands such as Nivea and SAP do not use the German language to stress their origins (Kelly-Holmes, 2005). The competences body care and software respectively are not familiar German competences in people's minds. As Kelly-Holmes (2005) point outs, the products and competences linked to particular countries are based on people's perceptions about these countries. These perceptions may be based on direct experience (e.g. through spending one's holidays in a foreign country), and in particular through what the media tell us about countries, their inhabitants and their characteristics. 


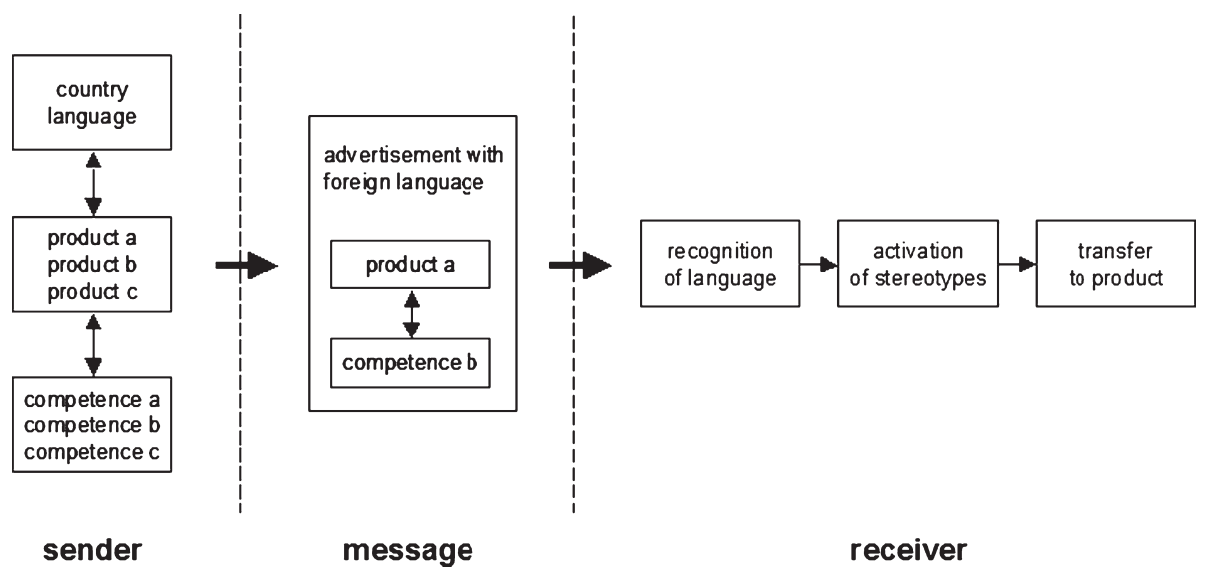

Figure 1 Symbolic associations of foreign languages in advertising from sender to receiver (Hornikx \& Starren, 2006)

If linguistic fetish is based on typical combinations of languages, countries, products and competences, a logical question is to ask how linguistic fetish in advertising exactly leads to more effective advertising. In order to make the process of the effects of linguistic fetish more insightful, Hornikx and Starren (2006) proposed a model describing how symbolic associations work in advertising (see Figure 1).

In this model, the perspective of companies that place advertisements containing a foreign language (cf. Kelly-Holmes, 2000, 2005) is combined with the perspective of receivers who process advertisements through which symbolic meaning is created (e.g. Cheshire \& Moser, 1994; Piller, 2001). The left-hand side of the model draws heavily on Kelly-Holmes (2000, 2005), which was discussed above. The thought processes of the receiver of the advertisement are represented at the right-hand side of the model. Imagine an advertisement for a perfume, in which a foreign language fragment is used ('La passion du quotidien'), and which indirectly refers to certain competences, such as elegance and style. A receiver of this advertisement will first recognise (or not) the language that is used, the French language. The receiver will then activate stereotypes of the country and of its inhabitants. Finally, these stereotypical associations are said to transfer to the product. If the receiver of the ad considers the French to be charming and elegant, the perfume will also be seen as charming and elegant (Piller, 2001). This makes the product more valuable and desirable, so that the ad becomes more persuasive. It is important to observe that this model has not yet been tested empirically. One of the elements on the side of the receiver of the advertising message that has not been tested is what associations are exactly activated through the use of a foreign language.

\section{Associations Evoked by the Use of Foreign Languages}

In the literature, many claims have been made about the associations evoked by the use of foreign languages in advertising (Haarmann, 1989; Kelly-Holmes, 2000; Piller, 2001). Haarmann (1989: 11), for instance, mentions a number of 
stereotypes that are evoked by the use of English and French in Japanese advertising. These stereotypes are linked to particular products. For English, Haarmann mentions 'international appreciation' (in the case of alcoholic beverages), 'reliability' (in the case of cars) and 'high quality' (in the case of television sets). However, such claims seem to be based on the stereotypes that the researcher recognises in a corpus of advertisements. Luna and Peracchio (2002) stressed the importance of examining more directly what associations are evoked by the use of a foreign language.

We are aware of two studies in which participants were asked to pick associations from a given list. In Fink (1977), participants indicated their associations with 20 anglicisms in German on 38 scales such as modernold-fashioned and appealing-repelling. In a study of English in Ecuador, Alm (2003) presented people in leading positions in advertising agencies with 21 concepts (such as 'internationality', 'modern life' and 'technology') and asked them to indicate with which of these concepts English could be associated. These two studies have limitations in that respondents were asked to choose from a number of predetermined concepts and could not mention associations of their own. As far as we know, it has never been empirically studied what associations are actually evoked by the use of foreign languages in advertising. ${ }^{1}$

In order to gain insight into the way the use of foreign languages contributes to increasing the persuasiveness of advertisements, answers need to be found to the questions raised by the various elements in the model in Figure 1 representing the way foreign language use in advertising works. In the first place, it is necessary to find out what associations are evoked by the use of foreign languages.

RQ 1: What associations are evoked by foreign languages in advertising?

In addition, the valence of the associations - positive, neutral or negative - that are evoked is also unclear. Foreign languages in advertising may evoke negative associations. There are, for instance, negative stereotypes about Spanish as the language of a 'poor, discriminated minority' in the USA (Piller, 1999: 334). Piller (1999: 334), however, remarks that 'brand namers' assume that receivers of an advertisement containing a foreign language will only select the positive associations that are evoked by the foreign language.

RQ 2: What is the valence of the associations that are evoked by foreign languages in advertising?

A third question that is relevant in this context relates to the connection between the associations people have with foreign languages in advertising and their appreciation of the advertisement. If more associations are evoked, or if more positive associations are evoked, does that lead to a better appreciation of the ad?

RQ 3: What is the relationship between the number and valence of the associations on the one hand and the appreciation of the advertisement on the other? 


\section{Method}

In order to answer the research questions, an experiment was conducted in which participants were given two identical ads that differed in the foreign language used: French, German or Spanish. Below, we will first present the material, the participants, and the design of the study. Subsequently, we will explain what instrumentation was used, and what procedure was followed.

\section{Material}

Participants were given concrete advertisements to stimulate them to write down associations with foreign language. In order to have participants differentiate explicitly between the use of different foreign languages, they were given two advertisements for the same product. The concrete advertisement for the product was carefully selected, as the kind of product is likely to influence the reactions to the foreign language that is used (see left-hand side of Figure 1). The product was neutral in the sense that neither France, Germany nor Spain were expected to have a higher 'legitimacy' to produce it: an electronic email receiver of the fictitious brand Geddit. The product, brand name, and layout of the advertisement were taken from Hornikx (2002). The English brand name was represented phonetically to give the brand an international (and non-French, non-German, non-Spanish) image. ${ }^{2}$ The ad was composed of an image of the product, a product indication in the foreign language ('mobiles elektronisches Postfach', 'courrier électronique mobile' or 'mensajes electrónicos móviles'), and the header 'Elegance' in a large font ('Eleganz', 'élégance', 'elegancia'). The header 'Elegance' was chosen because of the phonetic similarity of the word in the three languages. ${ }^{3}$ In order to ensure that each participant would recognise which foreign languages were concerned (cf. the right-hand side of Figure 1), the information accompanying the advertisements specified the languages concerned, and the product information was given in a Dutch translation. The three advertisements used in the experiment can be found in the Appendix.

\section{Participants}

The participants were Dutch students of Business Communication Studies. The questionnaires were distributed at the beginning of a lecture at the Radboud University Nijmegen. Two groups of students participated: (1) participants who did not study either of the two languages in the advertisements, and (2) participants who received advertisements of which one was presented in a language they studied themselves. These two subgroups were not targeted beforehand, but were identified after the questionnaires had been collected. The first group was composed of 42 students, who were on average $21.07(s d=1.79)$ years old, and of whom 90.5\% was female. Of the second group of 36 students, 50.0\% studied the Spanish language, 30.6\% the French language and $19.4 \%$ the German language. Students in this group were also mainly female students $(88.9 \%)$ with a mean age of $21.86(s d=2.33)$ years. The students received no reward for their participation. After the questionnaires had been collected, the real research purpose was revealed, and participants were thanked for their cooperation. The whole procedure took about $15 \mathrm{~min}$. There were no disturbances during the experiment. 


\section{Design}

The experiment used a within-subjects design: participants were given two advertisements with different foreign languages. At the same time, there was a between-subjects design, as each participant received one of the three versions of the questionnaire. In version 1, the French advertisement was followed by the German advertisement; in version 2, the German advertisement was followed by the Spanish advertisement; and in version 3, the Spanish advertisement was followed by the French advertisement. Each language was used once as the first language, and once as the second language. This design was chosen to rule out a possible order effect.

\section{Instrumentation}

The booklet started with an instruction, which stated that many advertisers use the same advertisements with translated copy in different countries to reduce costs. It was remarked that an important question on the basis of this practice is to ask whether a translation also entails a change in the meaning of the copy. Participants then read:

The question to you is as follows: what does the use of a slogan in a foreign language evoke for you? [...] You are free to use the same associations for each of the two advertisements. There is no such thing as wrong associations; simply write down what comes to your mind.

The two advertisements were each accompanied by a space with lines on which the participants could write down their associations. At the end of the questionnaire, the participants were asked a number of personal questions: the language they studied, their age and sex, and their preference for either of the two advertisements. This last question was asked in order to investigate the relationships between appreciation, and number and valence of associations.

\section{Procedure}

A number of participants were randomly discarded from analyses in order to have the same number of participants per version, namely 26 . Next, a list was made of all associations that had been written down for each of the three languages. In two cases, associations were not taken into account. First, associations were not listed when the participants unambiguously indicated that the association was not related to the language or country concerned but to the target audience (e.g. 'device for men'), to the company (e.g. 'negative association with the company'), to the brand (e.g. 'an old-fashioned brand'), to the product (e.g. 'handy product'), to the ad (e.g. 'simple ad'), to the relationships between these aspects (e.g. 'advertisement does not fit') or to the comprehension of the language (e.g. 'difficult to understand'). Second, an association was not taken into account when it was considered irrelevant, such as the association 'messages'. The number of associations not taken into account in these ways was rather low, namely about $30(5.4 \%$ of all associations). Associations that contained the same adjective but with different qualifications were taken together: 'a little bit mysterious' and 'very mysterious' were both classified as 'mysterious'. For the same reason, adjectives and 
related nouns, such as 'rapid' and 'rapidity' were counted as the same association.

On the basis of a Dutch dictionary of synonyms (Van Sterkenburg et al., 1996) and a Dutch thesaurus (Brouwers \& Claes, 1997) we put associations together in categories by mutual agreement. In this way, 17 categories were identified, such as 'simple', 'reliable' and 'modern'. As the word 'elegant' was used in the experimental material, associations related to it were put in the category 'elegant', even though 'elegant' could be placed in the category 'beautiful'. Finally, the valence of the associations (positive, negative or neutral) was assessed by mutual agreement. For instance, an association was considered positive when all of the authors considered it positive, or when two of them considered it positive and the third considered it neutral.

For each category, the total number of associations was counted; associations with a meaning opposite to the category label (e.g. 'not elegant' in the category 'elegant') were subtracted from the total number. A number of associations could not be classified into one of the categories (one Spanish association, five German associations and eight French associations). These associations were not taken into account when determining the relative frequency of the various categories of associations, but we did use them for assessing the valence of associations.

\section{Results}

This study was set up to provide insight into the kind and valence of associations evoked by foreign languages in advertisements, and into the relationships between the number and valence of these associations on the one hand, and the appreciation of the advertisement on the other. We will discuss the results for the kind of associations, the valence of the associations, and the relationships separately.

\section{Kind of associations}

In the presentation of the associations given by the participants, we will concentrate on the different categories, and not on the individual associations, as the total number of unique associations was 142. All the associations and categories, which were originally in Dutch, are presented in English (for examples, see Appendix). On average, participants gave 3.37 ( $s d=1.59$ ) associations per language. The first research question was about the kind of associations that are evoked by foreign languages in advertising. Table 1 shows the number and kinds of the associations listed by language and category.

As Table 1 shows, there are clear differences in the frequency with which associations in the 17 categories were used. These differences will be discussed by looking at the most frequent categories per language, and at the categories that were lacking for each language but that were present for the other languages. The top five categories in which most of the associations were given for the French language were 'beautiful', 'businesslike', 'simple', 'elegant' and 'boring'. The categories that occurred most frequently for the German language were 'businesslike', 'reliable', 'boring', 'bare' and 'simple'. For Spanish, finally, the most popular categories were 'beautiful', 'businesslike', 
Table 1 Number of associations in function of language and category (a minus sign indicates that a category contained more negative than positive variants for that language)

\begin{tabular}{|l|r|r|r|c||}
\hline Category & French & German & Spanish & Total \\
\hline Businesslike & 15 & 35 & 20 & 70 \\
\hline Beautiful & 42 & -4 & 21 & 67 \\
\hline Boring & 9 & 17 & 10 & 36 \\
\hline Simple & 14 & 10 & 5 & 29 \\
\hline Elegant & 11 & -6 & 11 & 28 \\
\hline Reliable & 5 & 20 & -1 & 26 \\
\hline Bare & 6 & 16 & 2 & 24 \\
\hline Modern & 4 & -1 & 12 & 17 \\
\hline Culture-specific items & 5 & 2 & 8 & 15 \\
\hline Technical & 2 & 9 & 0 & 11 \\
\hline Feeling & 5 & -1 & 3 & 9 \\
\hline Passion & 1 & 0 & 6 & 7 \\
\hline Playful & 2 & -1 & 4 & 7 \\
\hline Friendly & 0 & -3 & 4 & 7 \\
\hline Quality & 3 & 4 & 0 & 7 \\
\hline Expensive & 31 & -2 & -1 & 6 \\
\hline Melodious & 0 & 1 & 5 \\
\hline Total & 131 & 109 & 371 \\
\hline \hline
\end{tabular}

'modern', 'elegant' and 'boring'. A category that was unmentioned for the French language (but that was present for the Spanish language) was 'friendly'. Categories that were evoked for French and Spanish, but not for German were 'elegant', 'beautiful', 'friendly', 'playful', 'modern', 'feeling', 'melodious' and 'passion'. Categories that were lacking for Spanish, but present for French and German, were 'reliable', 'expensive', 'technical' and 'quality'.

\section{Valence of associations}

The second research question was about the valence of the associations. Positive, as well as negative and neutral associations were evoked for all three languages. Although positive associations were more frequent than neutral and negative associations $\left(\chi^{2}(1)=7.78, p<0.001\right.$, and $\chi^{2}(1)=7.05, p<0.001$, respectively), only about half of the associations (48.9\%) were positive. This general distribution across the three languages was also found for French and 
Spanish, but not for German. About $40 \%$ of the associations that were evoked for German were negative (see Table 2). ${ }^{4}$

\section{Relationships between the number and valence of associations and appreciation}

The third research question concerned the relationships between the number and valence of the associations, and the appreciation of the advertisement that evoked these associations. Each of the participants was given two advertisements with a different foreign language, and was asked to indicate which of the two he or she appreciated most. The relationships between the number and valence of the associations, and the appreciation of the advertisement were explored for two different groups of participants: (1) participants who had received two advertisements of which one was presented in a language they studied themselves, and (2) participants who had received a version of the material that contained two languages they did not study. It should be noted at the outset that the results for both groups hardly differed.

For participants who had not received a language they studied, there was no relationship between the number of associations of the two languages and the appreciation of the ads $\left(\chi^{2}(1)=2.06, p=0.15\right)$. This means that the language that participants preferred was not the language for which they had given the most associations. The preference for a language, however, was affected by the valence of the associations. Participants had the most appreciation for the language for which they had the highest number of positive associations $\left(\chi^{2}(1)=17.63, p<0.001\right)$, and also the lowest number of negative associations $\left(\chi^{2}(1)=11.73, p<0.01\right)$. The number of neutral associations was not important $\left(\chi^{2}(1)=1.27, p=0.26\right)$.

Similarly, for the participants who had received two languages of which they studied one, there was no relationship between the number of associations of the two languages and their appreciation of the ads $\left(\chi^{2}(1)=1.27\right.$, $p=0.26)$. Again, this implies that the language that participants appreciated most was not the language for which they had written down the most associations. As with the other group of participants, the appreciation for a language was affected by the valence of the associations. Participants preferred the language for which they had the highest number of positive associations $\left(\chi^{2}(1)=13.59, p<0.001\right)$, the lowest number of negative associations $\left(\chi^{2}(1)=\right.$ $3.82, p=0.05)$ and the lowest number of neutral associations $\left(\chi^{2}(1)=4.87\right.$, $p<0.05)$. Also, it was tested whether participants preferred the language that they studied. This was the case (binomial test, $p<0.01, n=34$ ). In fact, $76 \%$ of

Table 2 Valence of the associations per language in numbers and percentages

\begin{tabular}{|l|l|l|l|l|l|l|l|l||}
\hline \hline Valence & \multicolumn{2}{|c|}{ French } & \multicolumn{2}{c|}{ German } & \multicolumn{2}{c|}{ Spanish } & \multicolumn{2}{c|}{ Total } \\
\hline Positive & 92 & $55.7 \%$ & 62 & $35.6 \%$ & 79 & $57.7 \%$ & 233 & $48.9 \%$ \\
\hline Neutral & 44 & $26.7 \%$ & 41 & $23.6 \%$ & 33 & $24.1 \%$ & 118 & $24.8 \%$ \\
\hline Negative & 29 & $17.6 \%$ & 71 & $40.8 \%$ & 25 & $18.2 \%$ & 125 & $26.3 \%$ \\
\hline Total & 165 & $100 \%$ & 174 & $100 \%$ & 137 & $100 \%$ & 476 & $100 \%$ \\
\hline
\end{tabular}


the participants preferred the language that they studied themselves. It could be surmised that the language that they study has this important role, because participants have more positive and less negative associations for that language. Surprisingly, this proved not to be the case. Participants did not have more positive associations for the language they studied $(M=1.42$, $s d=1.18)$ than for the other language $(M=1.53$, $s d=1.28)(t(35)=0.43$, $p=0.67)$. Nor did participants have fewer negative associations for the language they studied $(M=0.64, s d=1.17)$ than for the other language $(M=0.72, s d=1.16)(t(35)=0.43, p=0.67)$.

In sum, participants preferred the ad with a language they studied themselves, and the ad with the highest number of positive associations and the lowest number of negative associations. It should be noted that the effects of the number of positive and negative associations appear not to be independent. In fact, there was a quite high negative correlation between the number of positive associations of an ad and the number of negative associations (first ad: $r(78)=-0.53, p<0.001$; second ad: $r \quad(78)=-0.33$, $p<0.01)$.

\section{Conclusion and Discussion}

This study was conducted to provide insight into the way foreign language use leads to higher persuasiveness of advertisements. We focused on the kind and valence of associations that are evoked by the use of foreign languages, and on how this relates to people's appreciation for the advertisement using foreign languages.

In the first place, we aimed at answering the question as to what associations are evoked in the minds of the ad receivers. The associations that the Dutch participants wrote down for the French, German and Spanish language were diverse. A part of the associations has certainly been influenced by the specific ad ('simple'), the product ('businesslike') and the utterance in the foreign language ('elegant'). Still, there was a large difference in the frequency with which 'elegant' was written down for the three languages. It found a place in the top five for French and Spanish, but participants wrote down 'not elegant' more frequently than 'elegant' for German. A short summary of the typical associations with the three languages in this study is 'beautiful', 'elegant' and 'feeling' for French, 'reliable', 'businesslike' and 'technical' for German, and 'beautiful', 'modern' and 'passion' for Spanish. It may be interesting to compare these results with the associations that researchers have attributed to languages in advertising on the basis of corpus research (Haarmann, 1989; Kelly-Holmes, 2005; Piller, 1999). Note that this is a rough comparison, as associations also depend on the products advertised in the multilingual ad. Associations with French that were shared by this experiment and corpus research are 'elegance' (Haarmann, 1989; Piller, 1999), 'beauty' (Kelly-Holmes, 2005) and other associations within categories distinguished here, such as 'attractiveness' (Haarmann, 1989) and 'femininity' (Kelly-Holmes, 2005; Piller, 1999). For German, 'technical' and 'quality' are associations that were also found in corpus studies (Kelly-Holmes, 2005). It appears then that there is a considerable correspondence between the 
associations given to multilingual advertisements by researchers and by lay people.

In the second place, our study aimed to answer the question as to whether these kinds of associations are only positive, as advertisers suppose (see Piller, 1999). In our experiment only half of the associations was positive. A quarter of the associations was neutral, and a quarter negative. This overall pattern was also found for the French and the Spanish language, but not for the German language. For this language in particular, there was a high percentage of negative associations. The overall low percentage of positive associations might be explained with reference to Kelly-Holmes' (2000) cultural competence hierarchy. The electronic email receiver is not a product that is typically related to France, Germany or Spain. The model in Figure 1 suggests that a typical combination of language, country, product and competence is a condition for optimal linguistic fetish. If the combination is less straightforward, neutral and negative associations are likely to be evoked. Obviously, there may also be very specific (e.g. historical) reasons for the evocation of more negative or more positive associations. For instance, the fact that German evoked a relatively large number of negative associations is in line with the negative image that Dutch youngsters have of Germany (Koentopp, 2003: 54). Whatever the reasons may be, our research shows that foreign language use in advertising does not always have the positive effect that is suggested in the literature.

Finally, our experiment aimed at exploring the relationships between the number and valence of the associations on the one hand, and the appreciation of advertisements on the other. Participants had to choose explicitly between the two advertisements for which they had noted down their associations. There was no relationship between the number of associations of the languages in the two ads and the appreciation of the ads: participants did not prefer the ad with the highest number of associations. Instead, they preferred the ad with the highest number of positive associations and the lowest number of negative associations. About half of the participants received two ads, one of which was in a language they studied as part of their university programme. The relationship described above also applied to these participants, but they also preferred the ad with the language they study, and this preference could not be explained by the number of positive and negative associations for this ad.

The links that were found between the number and valence of the associations, and the appreciation for the ad provides some support for the assumption that the persuasiveness of multilingual ads can be explained by the positive associations generated. The results in this study are rather preliminary, as they are based on only one type of product, a limited number of foreign words and an experimental setting where participants were explicitly asked to generate associations. However limited the generalisability of these results of this study may be, we hope that it will stimulate further research on how multilingual advertising may lead to persuasive effects. In view of the importance of the notion of fit suggested by the model in Figure 1, further research could, for instance, investigate the effect of typical and atypical combinations of languages, countries and products on the number and valence of the associations generated. In this way, such a study could 
provide more insight into the effect of symbolic associations on the appreciation of multilingual advertisements.

\section{Correspondence}

Any correspondence should be directed to Jos Hornikx, Business Communication Studies, Centre for Language Studies, Radboud University Nijmegen, P.O. Box 9103, 6500 HD Nijmegen, The Netherlands (j.hornikx@ let.ru.nl).

\section{Notes}

1. In one study, participants were free to write down their own observations on the basis of a multilingual advertisement (Luna \& Peracchio, 2005). However, partipants were not explicitly asked to write down associations related to the foreign language use.

2. Two reviewers pointed out that this choice might not have been optimal, because (1) the use of an English brand name for a technical product does not seem neutral, and (2) the phonetic representation may have connotations with the USA. Although we agree with these comments, we would like to emphasise that the choice for Geddit did not influence participants' reactions to the foreign languages as this brand name was used in all three advertisements.

3. The choice for the header 'Elegance' might have provided a stronger fit with the French language, as some scholars claim that it is associated more with French. However, similar comments can be made for the other two languages: the technological product may fit best with Germany, and the modernity of the product with Spain.

4. The total number of associations in Table 2 is higher than in Table 1 for two reasons. First, in Table 1 the number of associations opposite to the category label (e.g. 'not elegant' in the category 'elegant') was subtracted from the total number of associations. Second, the 14 associations that were not categorised in Table 1 are present in Table 2.

\section{References}

Alm, C.O. (2003) English in the Ecuadorian commercial context. World Englishes 22 (2), $143-158$.

Bhatia, T.K. (1992) Discourse functions and pragmatics of mixing: Advertising across cultures. World Englishes 11 (2/3), 195-215.

Brouwers, L. and Claes, F. (1997) Het Juiste Woord: Betekeniswoordenboek (6th ed.). Antwerpen/Den Haag: Standaard Uitgeverij/Sdu Uitgevers.

Cheshire, J. and Moser, L. (1994) English as a cultural symbol: The case of advertisements in French-speaking Switzerland. Journal of Multilingual and Multicultural Development 15 (6), 451-469.

European Commission (2006) Europeans and their languages. http://ec.europa.eu/ public_opinion/archives/ebs/ebs_243_en.pdf. Accessed 15.03.07.

Fink, H. (1977) 'Texas-Look' und 'Party-Bluse': Assoziative Effekte von Englischem im Deutschen. Wirkendes Wort 27, 394-402.

Gerritsen, M. (1996) Engelstalige productadvertenties in Nederland: Onbemind en onbegrepen. In R. van Hout and J. Kruijsen (eds) Taalvariaties: Toonzettingen en Modulaties op een Thema (pp. 67-85). Dordrecht: Foris.

Gerritsen, M., Korzilius, H., Van Meurs, F. and Gijsbers, I. (2000) English in Dutch commercials: Not understood and not appreciated. Journal of Advertising Research 40 (4), 17-31.

Haarmann, H. (1989) Symbolic Values of Foreign Language Use: From the Japanese Case to a General Sociolinguistic Perspective. Berlin: Mouton de Gruyter.

Hornikx, J. (2002) Vertrouwen in nieuwe producten van nieuwe merken in reclame. Tijdschrift voor Communicatiewetenschap 30 (3), 249-261. 
Hornikx, J. and Starren, M. (2006) The relationship between the appreciation and the comprehension of French in Dutch advertisements. In R. Crijns and C. Burgers (eds) Werbestrategien in Theorie und Praxis: Sprachliche Aspekte von Deutschen und Niederländischen Unternehmensoarstellungen und Werbekampagnen (pp. 129-145). Tostedt: Attikon.

Hornikx, J., Starren, M. and van Heur, B. (2004) Frans in Nederlandse advertenties: Drager van symbolische en letterlijke betekenis. Toegepaste Taalwetenschap in Artikelen $71(1), 61-68$.

Kelly-Holmes, H. (2000) Bier, parfum, kaas: Language fetish in European advertising. European Journal of Cultural Studies 3 (1), 67-82.

Kelly-Holmes, H. (2005) Advertising as Multilingual Communication. New York: Palgrave MacMillan.

Koentopp, D. (2003) Gruppenarbeit im Interkulturellen Kontext: Deutschland - Niederlände. Osnabrück: Dirk Koentopp.

Luna, D. and Peracchio, L. (2002) Uncovering the cognitive duality of bilinguals through word association. Psychology \& Marketing 19 (6), 457-476.

Luna, D. and Peracchio, L. (2005) Advertising to bilingual consumers: The impact of code-switching on persuasion. Journal of Consumer Research 31 (4), 760-765.

Petrof, J. (1990) L'utilisation des langues étrangères comme moyen d'augmenter l'efficacité de la publicité: Une approche expérimentale. Recherche et Applications en Marketing 5 (2), 1-16.

Piller, I. (1999) Iconicity in brand names. In M. Nänny and O. Fischer (eds) Form Miming Meaning: Iconicity in Language and Literature (pp. 325-341). Amsterdam: John Benjamins.

Piller, I. (2001) Identity constructions in multilingual advertising. Language in Society 30 (2), 153-186.

Piller, I. (2003) Advertising as a site of language contact. Annual Review of Applied Linguistics 23, 170-183.

Sella, H. (1993) L'emploi des langues étrangères dans la publicité grecque. La Linguistique 29 (1), 89-101.

van Sterkenburg, P., Van Dalen, M., Hooyman, M. and Verburg, M. (1996) Groot Woordenboek van Synoniemen en Andere Betekenisverwante Woorden. Utrecht/Antwerpen: Van Dale Lexicografie. 


\section{Appendix}

The advertisements used in the experiment
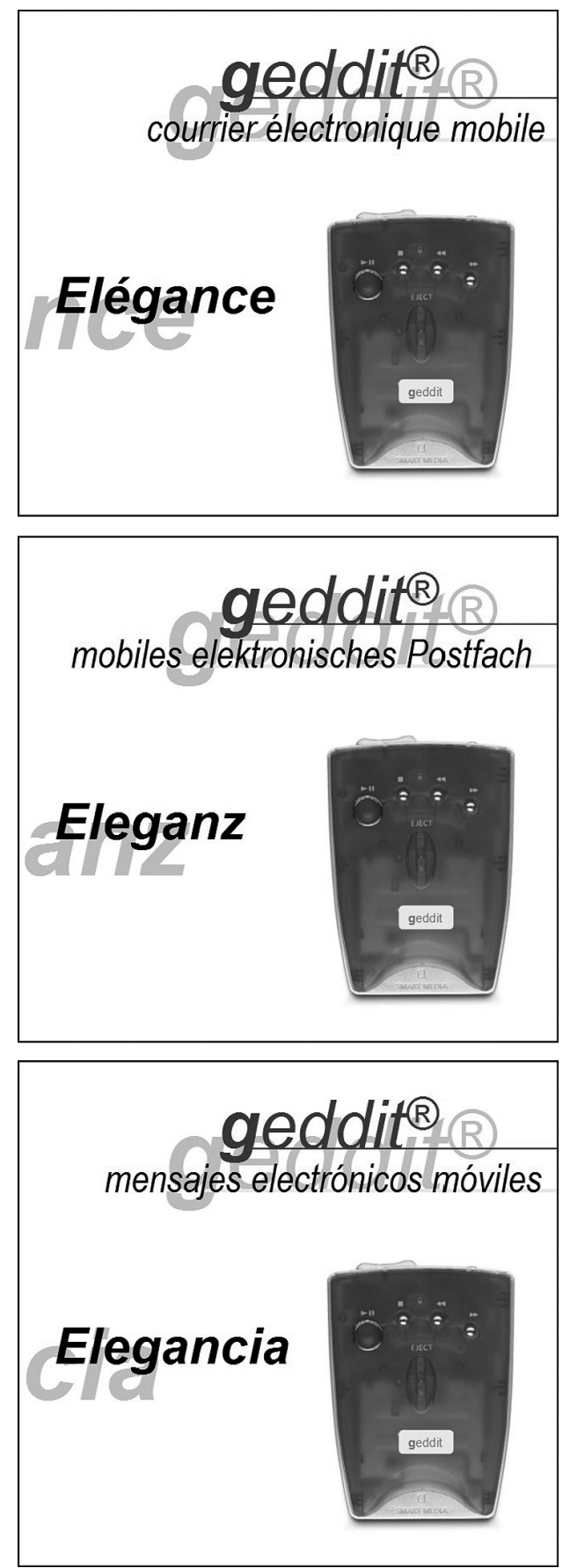


\section{Examples of associations per category in function of valence}

\begin{tabular}{|c|c|c|c|}
\hline category & positive & neutral & negative \\
\hline businesslike & professional & business & unprofessional \\
\hline beautiful & beautiful & classic & unattractive \\
\hline boring & not boring & - & boring \\
\hline simple & clear & simple & complicated \\
\hline elegant & elegant & - & not elegant \\
\hline reliable & reliable & - & unreliable \\
\hline bare & - & - & impersonal \\
\hline modern & modern & - & old-fashioned \\
\hline culture-specific items & beach & Juan Carlos & Eastern bloc bureaucracy \\
\hline technical & - & high-tec & not high-tec \\
\hline feeling & sensitive & soft & masculine \\
\hline passion & passion & temperament & - \\
\hline playful & playful & game & - \\
\hline friendly & friendly & - & arrogant \\
\hline quality & quality & - & - \\
\hline expensive & affordable & expensive & cheap \\
\hline melodious & melodious & melody & - \\
\hline
\end{tabular}

